\title{
The top research questions asked by people with lived depression experience in Alberta: a survey
}

\author{
Lorraine J. Breault PhD RPsych, Katherine Rittenbach PhD, Kelly Hartle PhD, \\ Robbie Babins-Wagner PhD RSW, Catherine de Beaudrap BA BEd, Yamile Jasaui MSc, Emily Ardell MD, \\ Scot E. Purdon PhD RPsych, Ashton Michael, Ginger Sullivan RN MN, \\ Aakai'naimsskai'piiaakii Sharon Ryder Unger, Lorin Vandall-Walker, Brad Necyk MFA, Kiara Krawec BA, \\ Elizabeth Manafò MHSc, Ping Mason-Lai MA
}

\section{Abstract}

Background: To support patient-oriented setting of priorities for depression research in Alberta, the Patient Engagement Platform of the Alberta Strategy for Patient Oriented Research's Support for People and Patient-Oriented Research and Trials Unit and Alberta Health Services' Addiction and Mental Health Strategic Clinical Network, along with partners in addictions and mental health, designed the Alberta Depression Research Priority Setting Project. The aim of the project was to survey patients, caregivers and clinicians/researchers in Alberta about what they considered to be the most important unanswered questions about depression.

Methods: The project adapted the James Lind Alliance Priority Setting Partnership method into a 6-step process to gather and prioritize questions about depression posed by people with lived depression experience, which included patients, caregivers, clinicians and health care practitioners.

Results: Implementation of the project, from initial data collection to final priority setting, took 10 months (August 2016 to June 2017). A total of 445 Albertans with lived experience of depression participated, ultimately identifying 11 priority depression research questions spanning the health continuum, life stages, and treatment and prevention opportunities.

Interpretation: This project is a fundamental step that has the potential to positively influence depression research. Including the voices of Albertans with lived experience will create advantages for depression research for Albertans, researchers and research funders, and for patient engagement in the research enterprise overall.

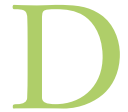
epression is a major public health issue in Canada. ${ }^{1}$ About $8 \%$ of adults aged $25-64$ years are projected to experience major depression at some time in their lives. ${ }^{2}$ Depression is estimated to account for at least $\$ 32.3$ billion of direct and indirect costs to this nation annually. ${ }^{3}$ Continued investment in research that explores prevention and treatment is needed, ${ }^{4,5}$ in particular through engaging patients (i.e., people with depression, family members and informal caretakers) in this endeavour to better ensure that research is relevant to their needs. Patient engagement occurs "when patients meaningfully and actively collaborate in the governance, priority setting, and conduct of research, as well as in summarizing, distributing, sharing, and applying its resulting knowledge." ${ }^{6}$ However, research findings suggest that medical research topics are selected predominantly by researchers and funding agencies, with little input from patients themselves, ${ }^{7}$ and that, even when patients are engaged in setting research priorities, their opinions are sometimes overlooked. ${ }^{8}$ Engaging people with lived experience of a health situation in setting research priorities is one structured way of influencing researchers and research funders to consider their opinions.
The goal of the Alberta Depression Research Priority Setting Project (ADRPSP) was to have patients and clinicians in Alberta identify the most important unanswered questions about depression by answering the research question "What are the patient and clinician priorities for depression research in Alberta?" The project was codesigned and coimplemented by the Patient Engagement Platform of the Alberta Strategy for Patient-Oriented Research's Support for People and Patient-Oriented Research and Trials Unit, Alberta Health Services' Addiction and Mental Health Strategic Clinical Network and the Alberta Depression Research Hub of the Canadian Depression Research and Intervention Network. In this paper, we describe the process used to survey patients,

Competing interests: None declared.

This article has been peer reviewed.

Correspondence to: Lorraine Breault, Ibreault@ualberta.ca

CMAJ Open 2018. DOI:10.9778/cmajo.20180034 
caregivers and clinicians on what they believe are unanswered questions about depression. We report our findings taking into account the Guidance for Reporting Involvement of Patients and the Public checklist criteria for patient and public involvement ${ }^{9}$ and the Checklist for Reporting Results of Internet E-Surveys. ${ }^{10}$

\section{Methods}

\section{Setting and participant recruitment}

The study focused on recruiting people who lived within the geographic boundaries of Alberta. The partner organizations recruited 14 members from their communities to form an ADRPSP Steering Committee consisting of 6 people with depression, 1 caregiver, 4 clinicians, 5 researchers and 2 members of the ADRPSP planning committee (some members represented more than 1 category, i.e., a person with depression who was also a clinician). A convenience sampling strategy was predominantly used to recruit people with depression, people who care for those with depression and health care professionals who treat people with depression.

Participants were recruited via advertisements on social media platforms (Twitter and Facebook), through websites of partner organizations and through network connections of Steering Committee members. In an effort to engage populations that have traditionally been voiceless in health research, including Métis and homeless people, a purposive sampling technique was used, employing established connections and relationships through partner organizations (e.g., leveraging positive connections at the Bissell Centre, Edmonton). A sampling frame was developed to address the study objectives by including people with lived experience with depression, who are justifiably considered "experts," 11 with representation from a broad demographic spectrum (e.g., age, ethnicity, immigration status).

\section{Study design}

The James Lind Alliance Priority Setting Partnership method brings patient and clinician groups together on an "equal footing" to produce a jointly agreed-on list of research priorities, which are recorded and made available to researchers and funders. ${ }^{11}$ A "funnel approach" is used: a larger sample of people with lived experience first identifies research questions about a health issue, a smaller sample ranks the questions, and a still-smaller sample prioritizes the final questions. ${ }^{11}$

The Patient Engagement Platform adapted the 4-step James Lind Alliance method into a 6-step process to ensure that the voices of people with lived experience of depression were included throughout the project. An egalitarian, consensus-building process was used, combining the perspectives of people with lived depression experience and clinicians. The ADRPSP is, therefore, classified on the "Collaborate" level of Patient and Researcher Engagement in Health Research Schematic. ${ }^{12}$ The implementation of the project, from initial data collection to final priority setting, took 10 months (August 2016 to June 2017).

\section{Step 1: Data gathering (online and paper survey)}

The Steering Committee codesigned the survey by consensus, with the goal of ensuring that people with lived experience of depression identify their concerns and unanswered questions about depression. A copy of the survey can be found in Appendix 1 (available at www.cmajopen.ca/content/6/3/E398/ suppl/DC1). The ISO-27001-compliant Snap Surveys online platform (https://www.snapsurveys.com/) was used and was hosted by Alberta Innovates - Health Solutions, with data stored on secured internal systems. Access to the application was limited by site licences, and the application was accessible from onsite/internal systems only. In addition, the Web host function was password protected.

Participants were informed that their participation would help inform the research community on the direction of research, focusing on questions that matter most to patients, families and others who support Albertans with depression. To facilitate data collection, participants were given a specific URL to access the questionnaire. They were not required to provide their name or contact information. The survey took 10-20 minutes to complete. No incentives were provided to complete the survey.

Paper copies of the questionnaire were disseminated to populations who may have had more limited online access: 100 paper surveys were taken to a Métis settlement in Buffalo Lake ( 9 returned [response rate $9 \%$ ]), and 25 paper surveys were distributed to homeless people at the Bissell Centre (13 returned [response rate $52 \%$ ]).

Survey responses were accepted between August and December 2016.

\section{Step 2: Question analysis and review}

After excluding responses to the online survey from outside Alberta $(n=192)$, Steering Committee members analyzed the data for diversity of representation. Diversity was analyzed periodically throughout the survey (on a weekly basis for the first 3 months and every other week for the last month) to inform the Steering Committee about representation across responses.

Next, the open-ended questions submitted by people with lived experience were reviewed. Duplicate questions were removed, as were questions that 2 or more Steering Committee members agreed did not meet the purpose of the project. The remaining questions were reviewed by the entire Steering Committee to ensure that they were easy to understand, were worded appropriately (without jargon or acronyms) and reflected the original intent of the questions submitted. In-person meetings allowed the Steering Committee to ensure the questions were being interpreted through a patient lens. ${ }^{13}$ The aim was to fully capture the nuances in language on the list of prioritized questions. A smaller subset of questions was assigned to dyads within the Steering Committee (i.e., 1 person with lived experience and 1 clinician) to formulate the research questions using the PICO (population, intervention, comparator, outcome) format, ${ }^{14}$ where possible.

\section{Step 3: Question rating (online survey)}

An online rating survey was created and the URL shared on Twitter and through contact networks of the Steering Committee. Over 1 week in June 2017, survey respondents identified 
which of the short-listed questions were most important using a 5-point Likert scale: not a priority, low priority, medium priority, high priority or undecided. Data were collected and managed with the use of REDCap electronic data capture tools, ${ }^{15}$ a secure and user-friendly application hosted at the University of Alberta. Access to the application was limited by site licences, was accessible from onsite/internal systems only and was password protected. Questions that were most frequently identified as "high priority" were ranked higher than or equal to other questions to establish the order of question importance. This ultimately generated a list of research questions rated in order of importance. No incentives were provided to complete the survey.

\section{Step 4: Question prioritization (in-person workshop)}

Twenty participants (11 Steering Committee members and 9 members of the public, including clinicians, health care professionals and people with lived experience) selected by recommendation of the Steering Committee attended a full-day workshop in June 2017 to identify the top 10 questions submitted by Albertans. In addition, 3 facilitators, 3 Patient Engagement Platform members and 2 observers (1 student and 1 evaluator) attended and supported the workshop but did not participate in ranking. This sample fits within the James Lind Alliance recommendation that prioritization workshops not exceed 30 participants. ${ }^{11}$ Before the workshop, participants were given a ranking tool listing the top-ranked 25 questions from the rating survey and were asked to prioritize the questions from most important to least important. At the workshop, a nominal group technique was used, whereby participants were divided into 3 groups to compare their personal rankings. Each group had a facilitator and a recorder to manage the dialogue and guide the process toward group consensus. After 2 iterative rounds of dialogue and small-group work, the overall rankings of each question were brought back to the collective group for final ranking, and 11 questions were identified (v. the James Lind Alliance suggestion of 10 questions, as 2 questions had equal rating).

\section{Step 5: Knowledge synthesis}

The Knowledge Translation Platform of the Support for People and Patient-Oriented Research and Trials Unit searched the available literature to determine to what extent, if any, the top 11 questions had been addressed by previous research (to be reported in a forthcoming manuscript). Manuscripts on the knowledge synthesis and literature search strategies, including the identification of knowledge gaps, are in process.

\section{Step 6: Knowledge translation}

The Patient Engagement Platform developed a final report ${ }^{16}$ in conjunction with the Steering Committee and planned, implemented and hosted a media launch that resulted in television, radio and print news coverage, as well as attendance by researchers. A separate paper discussing the patient engagement components of the ADRPSP has been published elsewhere. ${ }^{17}$ The Patient Engagement Platform is working with the identified partner organizations to facilitate dissemination and knowledge-translation opportunities by developing a knowledge-mobilization plan.

\section{Ethics approval}

The ADRPSP was approved by research ethics boards at the University of Alberta and Athabasca University. The research ethics boards approved "implied consent"; that is, consent was implied by the positive act of completing the survey.

\section{Results}

A total of 445 Albertans with lived experience of depression participated in identifying depression research questions (Table 1). Forty-nine people rated the research questions to inform the 25 medium- to high-priority questions.

\begin{tabular}{|c|c|}
\hline Characteristic/experience & $\begin{array}{c}\text { No. }(\%) \text { of } \\
\text { respondents } \\
n=445\end{array}$ \\
\hline \multicolumn{2}{|l|}{ Type of participant } \\
\hline Person with depression & $283(63.6)$ \\
\hline $\begin{array}{l}\text { Family member or caregiver of person with } \\
\text { depression }\end{array}$ & $74(16.6)$ \\
\hline $\begin{array}{l}\text { Health care professional caring for people } \\
\text { with depression }\end{array}$ & $28(6.3)$ \\
\hline Counsellor & $3(10.7)$ \\
\hline Nurse & $7(25.0)$ \\
\hline Psychiatrist & $1(3.6)$ \\
\hline Psychologist & $4(14.3)$ \\
\hline Social group worker & $1(3.6)$ \\
\hline Other & $12(42.8)$ \\
\hline Clinician treating depression & $14(3.1)$ \\
\hline Other* & $46(10.3)$ \\
\hline \multicolumn{2}{|l|}{ Sex } \\
\hline Male & $88(19.8)$ \\
\hline Female & $354(79.6)$ \\
\hline Did not report & $3(0.7)$ \\
\hline \multicolumn{2}{|l|}{ Age group, yr } \\
\hline $18-29$ & $76(17.1)$ \\
\hline 30-39 & $108(24.3)$ \\
\hline $40-49$ & $116(26.1)$ \\
\hline $50-59$ & 95 (21.3) \\
\hline $60-69$ & $40(9.0)$ \\
\hline $70-79$ & $8(1.8)$ \\
\hline$\geq 80$ & $2(0.4)$ \\
\hline \multicolumn{2}{|l|}{ Primary place of residence } \\
\hline Edmonton & $144(32.4)$ \\
\hline Calgary & $141(31.7)$ \\
\hline Elsewhere & $160(36.0)$ \\
\hline Immigrant status (between 2011 and 2016) & $10(2.2)$ \\
\hline
\end{tabular}


Table 1 (part 2 of 2): Survey participant demographic characteristics and experience with depression

\begin{tabular}{|c|c|}
\hline Characteristic/experience & $\begin{array}{l}\text { No. }(\%) \text { of } \\
\text { respondents } \\
n=445\end{array}$ \\
\hline \multicolumn{2}{|l|}{ Ethnic origin† } \\
\hline Canadian & $287(64.5)$ \\
\hline European & $150(33.7)$ \\
\hline East European & $29(6.5)$ \\
\hline Métis & $25(5.6)$ \\
\hline North American & $16(3.6)$ \\
\hline First Nation & $13(2.9)$ \\
\hline Asian & $11(2.5)$ \\
\hline South American & $6(1.3)$ \\
\hline African & $5(1.1)$ \\
\hline Middle Eastern & $5(1.1)$ \\
\hline Central American & $3(0.7)$ \\
\hline Inuit & $2(0.4)$ \\
\hline Other & $6(1.3)$ \\
\hline Prefer not to say & $5(1.1)$ \\
\hline \multicolumn{2}{|c|}{ Experience with depression $(n=420)$} \\
\hline Lifetime & $119(28.3)$ \\
\hline$>5 \mathrm{yr}$ & $159(37.8)$ \\
\hline $3-5 \mathrm{yr}$ & $39(9.3)$ \\
\hline $1-2 \mathrm{yr}$ & $28(6.7)$ \\
\hline$<1 \mathrm{yr}$ & $12(2.8)$ \\
\hline New diagnosis of depression & $4(1.0)$ \\
\hline Other & $15(3.6)$ \\
\hline Recovered from depression & $44(10.5)$ \\
\hline \multicolumn{2}{|c|}{ No. of months in year with depression experience $(n=352)$} \\
\hline $10-12$ & $164(46.6)$ \\
\hline 7-9 & $32(9.1)$ \\
\hline $4-6$ & $62(17.6)$ \\
\hline$\leq 3$ & $94(26.7)$ \\
\hline \multicolumn{2}{|c|}{$\begin{array}{l}\text { *Nurse educator, certified diabetes educator, bail supervisor, clinical exercise } \\
\text { physiologist, clinical scientist, dietitian, holistic nutritionist, counsellor (intern), life } \\
\text { coach, massage therapist, medical laboratory technologist, neurologist, } \\
\text { paramedic, occupational therapist, registered acupuncturist, senior quality } \\
\text { improvement consultant. } \\
\text { †Some participants self-identified in more than } 1 \text { group. }\end{array}$} \\
\hline
\end{tabular}

The ADRPSP was successful in gaining representation from people with lived depression experience at every step. In step 1 (data gathering), more than three-quarters of the respondents (357 [80.2\%]) identified as people with depression or as family members or caregivers of a person with depression. Within this population, 159/420 (37.8\%) had more than 5 years' experience with depression, and $119 / 420(28.3 \%)$ identified a lifetime of experience with depression. Nearly all participants $(44[90 \%])$ in step 3 (question rating) identified as having some experience with depression, as did more than half of participants (12 [60\%]) in step 4 (question prioritization).

The summary of outputs of the project across each of the 6 steps is provided in Table 2 . The final 11 priority research questions are identified in Figure 1.

\section{Interpretation}

In this study, we used a systematic and collaborative approach to identify 11 priority questions for depression research from the perspective of Albertans with lived experience of the condition. People with lived experience of depression and clinicians were involved in all steps of the research question identification and prioritization process. Aligning patient and clinician interests is challenging. The necessary "social conditions for dialogue" necessary for this alignment do not simply appear; therefore, an appropriate methodology should include strategies for developing mutual trust and commitment from otherwise disparate groups. ${ }^{18}$

This strategy presents many advantages for patients, clinicians and researchers and for the patient engagement in research enterprise itself. First, as suggested by the International Association for Public Participation's spectrum of public participation, ${ }^{19}$ the higher the degree of participation within research-priority-setting activities, the more accurately the results reflect the community. ${ }^{12}$ In the current study, more than three-quarters of the initial respondents identified as having lived experience of depression. The effects of this degree of participation may be illustrated by the extent to which the prioritized research questions span the health continuum, considering different life stages, treatments and prevention opportunities. The comprehensiveness of the questions reflects the complexity of depression and the multiple ways in which it affects the well-being of those affected. Second, the present study presents an opportunity to address research priorities that are meaningful to Albertans. Researchers have suggested that priorities established by people with lived experience are better aligned with the complex experience of living with disease and make it easier to gain broader collaboration from patients across the research activity spectrum. ${ }^{18,20}$ This approach recognizes patient contributions as valuable, acknowledging the expertise brought forward from patients' own experience. ${ }^{21,22}$

Although the James Lind Alliance Priority Setting Partnership method incorporates a simultaneous review of the literature to validate research uncertainties, the ADRPSP validated research questions through the creation of common themes that emerged from survey respondents, workshop participants and Steering Committee members. Questions were not systematically filtered based on existing research before the prioritization process began; therefore, we believe that the results authentically reflect the voices and perspectives of Albertans, including people with lived experience of depression. The literature on patient engagement suggests several benefits from such meaningful representation, including improved quality of research design, increased participant enrolment and decreased attrition in research studies, wider 


\begin{tabular}{|c|c|}
\hline Process & Output \\
\hline - & - 14-member Steering Committee formed \\
\hline $\begin{array}{l}\text { Step 1: Data gathering } \\
\text { (participant online and paper } \\
\text { survey), August-December } \\
2016\end{array}$ & $\begin{array}{l}\text { - } 445 \text { respondents (from Alberta only) } \\
\text { - } 1270 \text { questions and comments on depression received }\end{array}$ \\
\hline $\begin{array}{l}\text { Step 2: Question analysis and } \\
\text { review (Steering Committee), } \\
\text { August-December } 2016\end{array}$ & $\begin{array}{l}\text { - } 350 \text { questions removed that were submitted by participants } \\
\text { residing outside Alberta from how many respondents? } \\
\text { - } 724 \text { questions removed owing to duplication } \\
\text { - } 196 \text { questions reformulated into PICO (population, } \\
\text { intervention, comparator, outcome) research question } \\
\text { format }{ }^{14} \text { and refined (e.g., removed jargon) } \\
\text { - Short list of } 66 \text { research questions across } 7 \text { categories went } \\
\text { forward for final priority setting (in order: diagnosis and } \\
\text { treatment; society, culture and environment; medication, } \\
\text { biology and physiology; child and youth; access, service, } \\
\text { funding and policy; training and education; and family and } \\
\text { behaviour) }\end{array}$ \\
\hline $\begin{array}{l}\text { Step 3: Question rating } \\
\text { (participant online survey), } 1 \mathrm{wk} \\
\text { in June } 2017\end{array}$ & $\begin{array}{l}\text { - } 49 \text { participants rated } 66 \text { research questions (through online } \\
\text { survey) } \\
\text { - } 25 \text { medium- to high-priority questions (most commonly } \\
\text { asked) identified }\end{array}$ \\
\hline $\begin{array}{l}\text { Step 4: Question prioritization } \\
\text { (in-person participant } \\
\text { workshop), } 1 \mathrm{~d} \text { in June } 2017\end{array}$ & $\begin{array}{l}\text { - } 20 \text { participants prioritized } 11 \text { research questions } \\
\text { (3 facilitators, } 3 \text { Patient Engagement Platform members and } \\
2 \text { observers attended and supported workshop but did not } \\
\text { participate in ranking) } \\
\text { - } 14 \text { remaining questions not selected in the top } 11 \text { were } \\
\text { deemed worthy of consideration for future depression } \\
\text { research }\end{array}$ \\
\hline $\begin{array}{l}\text { Step 5: Knowledge synthesis } \\
\text { (Patient Engagement Platform } \\
\text { and knowledge translation), } \\
\text { July-October } 2017\end{array}$ & $\begin{array}{l}\text { - } 25 \text { rapid reviews of depression research questions } \\
\text { conducted }\end{array}$ \\
\hline $\begin{array}{l}\text { Step 6: Knowledge translation } \\
\text { (Patient Engagement Platform } \\
\text { and knowledge translation), } \\
\text { November 2017-January } 2018 \\
\text { and ongoing }\end{array}$ & $\begin{array}{l}\text { - Dissemination and knowledge mobilization opportunities } \\
\text { - Public report }{ }^{16} \text { launched to media January } 2018\end{array}$ \\
\hline
\end{tabular}

application of research findings and overall improved research effectiveness. $^{21,23,24}$ Therefore, we believe that using the results from our study can assist in closing the knowledge-to-action gap $^{25}$ by mobilizing timely and relevant data to inform clinical care and research.

Recent research suggests that building collaborative relationships between the patient and researcher requires an informed and compassionate understanding of how to effectively and efficiently involve patients in a meaningful and feasible way. ${ }^{26}$ The present study helps illustrate outcomes of meaningful patient and researcher engagement, building on other such work in Canada. ${ }^{20,27-35}$ It also contributes to the growth of evidence that people with lived experience are valuable research partners.

\section{Limitations}

Several important limitations should be considered when applying our findings. First, the convenience-sampling strat- egy may have resulted in bias due to over- and underrepresentation of subgroups compared to the population of interest. This inherent limitation was addressed in part by continuous review of demographic characteristics of participants who completed the online survey and question-ranking steps. Although the survey had good reach, some groups were underrepresented, which is an ongoing challenge recognized in the patient-engagement literature. ${ }^{36}$ Committed efforts were made to reach these populations; however, recruitment from these groups was not very successful. Furthermore, we could not calculate a response rate because the total sample number was unknown. To mitigate this issue in future research, a 2-step process could be used: self-identified participants first agree to participate in the study, and, once this is documented, they are sent the questionnaire to complete, thereby allowing calculation of the response rate.

Second, the possible subjective influence of Steering Committee members and patients, particularly in the smaller 


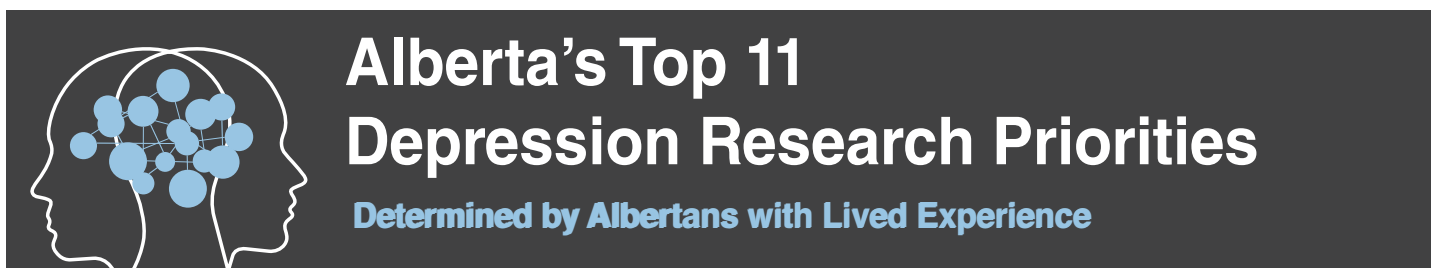

\begin{tabular}{|c|c|c|}
\hline 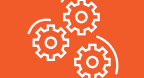 & 1 & Which treatment therapy or method is more successful for long term remission or recovery? \\
\hline & 2 & What are the long term physical implications of pharmacotherapy for treating depression? \\
\hline & 3 & $\begin{array}{l}\text { For various treatment options (eg. psychotherapy, individual vs. group psychotherapy and } \\
\text { psychosocial support), what are the advantages in terms of cost, effectiveness, relapse } \\
\text { prevention and safety? }\end{array}$ \\
\hline & 4 & $\begin{array}{l}\text { What are the prevention strategies/tactics for reducing self-harm and suicide in children, } \\
\text { youth and adults with depression? }\end{array}$ \\
\hline & 5 & What changes to the health care system will increase access to psychological services? \\
\hline & 6 & $\begin{array}{l}\text { What changes in the health care system will result in shortened wait times for } \\
\text { depression services? }\end{array}$ \\
\hline & 7 & Can diet or exercise affect the development of depression? \\
\hline & 8 & $\begin{array}{l}\text { What are the functional, social, intellectual, physical and psychological problems experienced by } \\
\text { children and teens living with an immediate family member who has depression? }\end{array}$ \\
\hline
\end{tabular}

$9 \begin{aligned} & \text { What interventions are effective in preventing and treating workplace depression and reducing } \\ & \text { stigma associated with depression in the workplace? }\end{aligned}$

10 Are there structural or functional changes in the brain due to antidepressant therapy during brain development?

11 What is the role of family in the treatment and trajectory of depression?

Alberta Depression Research Priority Setting Project (2017, August 10). [Alberta's Top 11 Depression Research Priorities: Determined by Albertans with Lived Experience] [Infographic]. Proceedings from the final workshop with the Alberta Depression Research steering committee and workshop participants, Edmonton AB June 12, 2017.
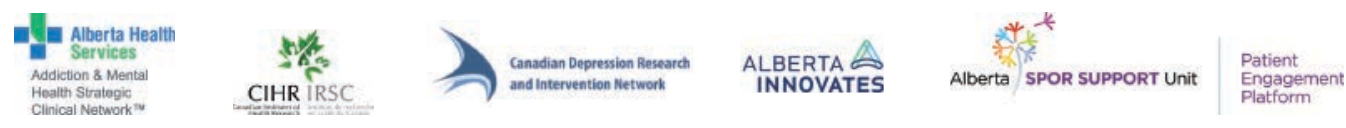

Figure 1: Alberta's top 11 depression research priorities.

group that completed the final prioritization of the research questions, should be considered in establishing research priorities to ensure that decisions are not informed solely by 1 type of evidence.
Third, a small group ranked the 25 research questions (step 3). Although it is expected that the sampling frame narrows throughout the 6 steps, ${ }^{11} 2$ factors may have decreased the number of people who might have participated at this 
step: a limited time frame (1 week) for completing the ranking and the fact that the ranking occurred during the summer, which may have decreased the available sample.

Considering these limitations, the Steering Committee relied on the recurrence of themes (i.e., saturation) as one indicator of representativeness, while continuously updating our strategies to solicit input from underrepresented populations. Future priority setting would focus on increasing representation from male participants, rural communities, immigrants and ethnically diverse communities to ensure that priorities are representative of all Albertans with depression. The specific demographic profile of Alberta would need to be considered, with $15.8 \%$ of the population reporting Aboriginal identity. ${ }^{37}$

\section{Conclusion}

We hope that the outcomes of the ADRPSP will better align research objectives with the needs of Albertans with lived experience of depression and will lead to funders' identifying some or all of these top 11 research questions as qualifying for monetary resource allocation and, as a result, to research. ${ }^{21}$ Future studies can adapt this process to actively engage patients throughout the research cycle. It is expected that this strategy will promote greater understanding of and insight into depression research, while continuously building rapport with people with lived depression experience as central to research processes. ${ }^{38,39}$

\section{References}

1. Patten SB. Problems from the past and prevention for the future. Can F Psychiatry 2015;60:4-5.

2. Making the case for investing in mental bealth in Canada. Ottawa: Mental Health Commission of Canada; 2013.

3. Healthy brains at work: estimating the impact of workplace mental bealth benefits and programs. Ottawa: Conference Board of Canada; 2016.

4. Options for improving access to counselling, psychotherapy and psychological services for mental health problems and illnesses. Ottawa: Mental Health Commission of Canada; 2017.

5. Strengthening the case for investing in Canada's mental health system: economic considerations. Ottawa: Mental Health Commission of Canada; 2017.

6. Strategy for patient-oriented health research - Patient Engagement Framework. Ottawa: Canadian Institutes of Health Research; (modified 2014 July 2). Available: www.cihr-irsc.gc.ca/e/48413.html (accessed 2018 July 31).

7. Tallon D, Chard J, Dieppe P. Relation between agendas of the research community and the research consumer. Lancet 2000;355:2037-40.

8. Stewart RJ, Caird J, Oliver K, et al. Patients' and clinicians' research priorities. Health Expect 2011;14:439-48.

9. Staniszewska S, Brett J, Simera I, et al. GRIPP2 reporting checklists: tools to improve reporting of patient and public involvement in research. BMF 2017; 358:j3453.

10. Eysenbach G. Improving the quality of Web surveys: the Checklist for Reporting Results of Internet E-Surveys (CHERRIES). 7 Med Internet Res 2004;6:e34.

11. About Priority Setting Partnerships. Southampton (UK): James Lind Alliance, National Institute for Health Research Evaluation, Trials and Studies Coordinating Centre, University of Southampton; 2018. Available: www.jla.nihr. ac.uk/about-the-james-lind-alliance/about-psps.htm (accessed 2018 July 31).

12. Amirav I, Vandall-Walker V, Rasiah J, et al. Patient and researcher engagement in health research: a parent's perspective. Pediatrics 2017;140:e20164127.

13. Fox S. Communication and interprofessional practice: collective sensemaking work [dissertation]. Burnaby (BC): Simon Fraser University; 2015.

14. Defining your question: PICO and PS. National Collaborating Centre for Methods and Tools. Available: www.nccmt.ca/knowledge-repositories/search/ 138 (accessed 2018 Sept. 13).

15. Harris PA, Taylor R, Thielke R, et al. Research electronic data capture (REDCap) - a metadata-driven methodology and workflow process for providing translational research informatics support. 7 Biomed Inform 2009;42: 377-81.

16. Alberta's top 11 priorities for depression research. Questions Albertans with first-hand experience of depression want answered. Addiction and Mental
Health Strategic Clinical Network, Alberta Health Services. Available: https:// albertainnovates.ca/wp-content/uploads/2018/02/Alberta-Depression-Research -Priority.pdf (accessed 2018 Sept. 13).

17. Breault LRK, Hartle K, Babins-Wagner R, et al. People with lived experience (PWLE) of depression: the process of engagement and research priority setting in Alberta. Res Involv Engagem. In press.

18. Abma TA, Broerse JE. Patient participation as dialogue: setting research agendas. Health Expect 2010;13:160-73.

19. IAP2 spectrum. International Association for Public Participation. Available: https://iap2canada.ca/Resources/Documents/0702-Foundations-Spectrum-MW -rev2\%20(1).pdf (accessed 2018 Sept. 13).

20. Boivin A, Lehoux $\mathrm{P}$, Lacombe $\mathrm{R}$, et al. Involving patients in setting priorities for healthcare improvement: a cluster randomized trial. Implement Sci 2014;9:24.

21. Duffett L. Patient engagement: what partnering with patient in research is all about. Thromb Res 2017;150:113-20.

22. Hibbard JH, Greene J. What the evidence shows about patient activation: better health outcomes and care experiences; fewer data on costs. Health Aff (Millwood) $2013 ; 32: 207-14$.

23. Esmail L, Moore E, Rein A. Evaluating patient and stakeholder engagement in research: moving from theory to practice. 7 Comp Eff Res 2015;4:133-45.

24. Forhan M, Risdon C, Solomon P. Contributors to patient engagement in primary health care: perceptions of patients with obesity. Prim Health Care Res Dev 2013;14:367-72

25. Graham ID, Logan J, Harrison MB, et al. Lost in knowledge translation: Time for a map? 7 Contin Educ Health Prof 2006;26:13-24.

26. Manafò E, Petermann L, Mason-Lai P, et al. Patient engagement in Canada: a scoping review of the 'how' and 'what' of patient engagement in health research [published erratum in Health Res Policy Syst 2018;16:24]. Health Res Policy Syst 2018;16:5.

27. Jones JM, Bhatt J, Avery J, et al. Setting research priorities for kidney cancer. Eur Urol 2017;72:861-4.

28. Manns B, Hemmelgarn B, Lillie E, et al. Setting research priorities for patients on or nearing dialysis. Clin 7 Am Soc Nephrol 2014;9:1813-21.

29. Rees SE, Chadha R, Donovan LE, et al. Engaging patients and clinicians in establishing research priorities for gestational diabetes mellitus. Can 7 Diabetes 2017;41:156-63.

30. D'Andreamatteo C, Davison KM, Vanderkooy P. Defining research priorities for nutrition and mental health: insights from dietetics practice [published erratum in Can 7 Diet Pract Res 2016;77:55-6]. Can 7 Diet Pract Res 2016;77: $35-42$.

31. Etchegary H, Bishop L, Street C, et al. Engaging patients in health research: identifying research priorities through community town halls. BMC Health Serv Res 2017;17:192.

32. Flaman LM, Nykiforuk CI, Plotnikoff RC, et al. Exploring facilitators and barriers to individual and organizational level capacity building: outcomes of participation in a community priority setting workshop. Glob Health Promot 2010; 17:34-43.

33. Regier DA, Bentley C, Mitton C, et al. Public engagement in priority-setting: results from a pan-Canadian survey of decision-makers in cancer control. Soc Sci Med 2014;122:130-9.

34. Restall GJ, Carnochan TN, Roger KS, et al. Collaborative priority setting for human immunodeficiency virus rehabilitation research: a case report. Can 7 Occup Ther 2016;83:7-13.

35. Walton NA, Martin DK, Peter EH, et al. Priority setting and cardiac surgery: a qualitative case study. Health Policy 2007;80:444-58.

36. Arkind J, Likumahuwa-Ackman S, Warren N, et al. Lessons learned from developing a patient engagement panel: an OCHIN report. 7 Am Board Fam Med 2015;28:632-8.

37. Number and distribution of the population reporting an Aboriginal identity and percentage of Aboriginal people in the population, Canada, provinces and territories, 2011 [table]. Ottawa: Statistics Canada; (modified 2015 Dec. 23). Available: www12. statcan.gc.ca/nhs-enm/2011/as-sa/99-011-x/2011001/tbl/tbl02-eng.cfm (accessed 2018 July 31)

38. Baker GR. Evidence boost: a review of research highlighting how patient engagement contributes to improved care [report]. Ottawa: Canadian Foundation for Healthcare Improvement; 2014.

39. Brett J, Staniszewska S, Mockford C, et al. A systematic review of the impact of patient and public involvement on service users, researchers and communities. Patient 2014;7:387-95.

Affiliations: Department of Psychiatry (Breault, Rittenbach, Hartle, Sullivan), Faculty of Medicine \& Dentistry, University of Alberta; Faculty of Pharmacy and Pharmaceutical Sciences (Necyk), University of Alberta, Edmonton, Alta.; Calgary Counselling (Babins-Wagner); Hotchkiss Brain Institute (Jasaui), University of Calgary; The Alex Community Health Centre (Ardell); Explorror (Michael), Calgary, Alta.; Parkland School Division (de Beaudrap), Spruce Grove, Alta.; Shinah House Foundation (Ryder Unger), Lethbridge, Alta.; Alberta Health Services (Purdon), Edmonton, Alta.; Athabasca University (Krawec, Manafò, Mason-Lai), Athabasca Alta.; Edmonton, Alta. (Vandall-Walker) 
Contributors: Elizabeth Manafò, Ping Mason-Lai, Lorraine Breault, Katherine Rittenbach and Kiara Krawec were involved in drafting the manuscript and revising it critically for important intellectual content. All of the authors made substantial contributions to the conception and design of the study and to data acquisition, analysis and interpretation, gave final approval of the version to be published and agreed to be accountable for all aspects of the work.

Funding: The Patient Engagement Platform of the Alberta Strategy for Patient-Oriented Research's Support for People and Patient-Oriented Research and Trials Unit gratefully acknowledges the funding received from the Canadian Institutes of Health Research - Strategy for PatientOriented Research and Alberta Innovates. The authors gratefully acknowledge Academic Research Fund funding from the Academic Research Committee, Athabasca University, which allowed this manuscript to be published in an open-access journal.

Acknowledgements: The authors acknowledge the partnership with Alberta Health Services' Addiction and Mental Health Strategic Clinical Network and the Alberta Depression Research Hub of the Canadian Depression Research and Intervention Network. They also acknowledge the support of Heidi Chorzempa from Performance Management and Evaluation, Alberta Innovates for her contributions to the survey design, building and implementation. The authors are grateful for the in-kind contributions and support from Alberta Health Services, Alberta Innovates and the Knowledge Translation and Data Platforms of the Alberta Strategy for Patient-Oriented Research's Support for People and Patient-Oriented Research and Trials Unit (AbSPORU). The authors acknowledge the critical contributions of time and energy by those (people with lived experience of depression, clinicians and health care professionals) who participated in the priority-setting workshop in June 2017: Bryan Meetsma, Glenda Maru, Janet Bodnar, Kristina Devoulyte, Laurie Sutherland, Lynne Kaluzniak, Ofelia Leon-Featherstone and Steve Gaspar. The authors also thank the following facilitators for supporting the priority-setting workshop: Levi Borejko, Lisa Petermann (Patient Engagement Platform) and the meeting recorders, Robyn Laczy (Patient Engagement Platform) and Sennait Yohannes (Patient Engagement Platform). Acknowledgement to Lona Leiren of Carr Leiren and Associates for evaluation support of the Alberta Depression Research Priority Setting Project. The authors further acknowledge and thank the AbSPORU Patient Engagement Platform Lead, Virginia Vandall-Walker, for her strategic direction, endorsement and support - both financial and in-kind - of this project.

Supplemental information: For reviewer comments and the original submission of this manuscript, please see www.cmajopen.ca/content/6/3/ E398/suppl/DC1 